\title{
Do age-related macular degeneration genes show association with keratoconus?
}

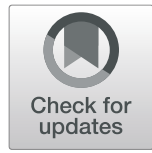

Ke Cao ${ }^{1,2}$, Srujana Sahebjada ${ }^{1,2}$, Andrea J. Richardson ${ }^{1}$ and Paul N. Baird ${ }^{2 *}$

\begin{abstract}
Background: Keratoconus (KC) is a common corneal condition with an unknown gender predominance. Although numerous studies have investigated the genetic component of $\mathrm{KC}$, no specific genes have yet been attributed to the condition. We recently reported posterior segment changes occurring in the eyes of KC patients. However, it is not clear whether these changes are part of KC pathogenesis or reflect changes in anatomical features of the eye manifested by changes at the cornea. Given retinal changes represent the main characteristics observed in agerelated macular degeneration (AMD) and that pleiotropy has been demonstrated between different eye diseases, we wished to assess if known AMD associated genes were also associated with KC.

Methods: A total of $248 \mathrm{KC}$ subjects and 366 non-KC (control) subjects were recruited from public and private clinics in Melbourne for this analysis. Nineteen single nucleotide polymorphisms (SNPs) previously associated with AMD, including rs10490924 (ARMS2/HTRA1), rs10737680 (CFH), rs13278062 (TNFRSF10A), rs1864163 (CETP), rs2230199 (C3), rs3130783 (IER3/DDR1), rs334353 (TGFBR1), rs3812111 (COL10A1), rs429608 (C2/CFB), rs4420638 (APOE), rs4698775 (CF), rs5749482 (TIMP3), rs6795735 (ADAMTS9), rs8017304 (RAD51B), rs8135665 (SLC16A8), rs920915 (LIPC), rs943080 (VEGFA), rs9542236 (B3GALTL) and rs13081855 (COL8A1/FILIP1L), were genotyped in this cohort. Logistic regression was applied to evaluate the association between these SNPs and KC on both genders together, as well as each gender separately. Linear regression was also applied to assess the association between SNPs and corneal curvature. Bonferroni correction was applied to adjust for multiple testing.

Results: Genotyping data were available for 18 SNPs. The SNP, rs6795735 (ADAMTS9) was significantly associated with KC $\left(p=3.5 \times 10^{-4}\right)$ when both genders were assessed, whereas rs5749482 (TIMP3) was only associated in males $\left(p=7.7 \times 10^{-4}\right)$ following Bonferroni multiple correction. However, when the covariates of age and gender were included, the associations became non-significant. In addition, none of the SNPs appeared significant for corneal curvature.

Conclusions: Our study suggested a potential association of rs6795735 in the ADAMTS9 gene and rs5749482 in the TIMP3 gene in KC and that different associations may be gender specific. Overall, SNPs initially identified as associated with AMD following multiple correction may be further impacted by other factors such as age or gender and further studies are needed to resolve this issue.
\end{abstract}

Keywords: Keratoconus, Gender, Genetic, Age-related macular degeneration

\footnotetext{
* Correspondence: pbaird@unimelb.edu.au

${ }^{2}$ Department of Surgery, Ophthalmology, The University of Melbourne, 32

Gisborne Street, East Melbourne, VIC 3000, Australia

Full list of author information is available at the end of the article
}

(c) The Author(s). 2019 Open Access This article is distributed under the terms of the Creative Commons Attribution 4.0 International License (http://creativecommons.org/licenses/by/4.0/), which permits unrestricted use, distribution, and reproduction in any medium, provided you give appropriate credit to the original author(s) and the source, provide a link to the Creative Commons license, and indicate if changes were made. The Creative Commons Public Domain Dedication waiver (http://creativecommons.org/publicdomain/zero/1.0/) applies to the data made available in this article, unless otherwise stated. 


\section{Background}

Keratoconus $(\mathrm{KC})$ is a progressive, bilateral and asymmetric corneal condition characterised by corneal thinning which leads to significant visual impairment [1] and accounted for $31 \%$ of all corneal grafts in Australia in 2018 [2]. Although spectacles, contact lens or other optical interventions can often correct some, or all visual acuity, they have no role in preventing its progression [3]. Corneal collagen cross-linking (CXL) has been shown to slow KC progression by increasing the stiffness of the cornea, but this can only be done at the early stage of disease when there is maximal corneal thickness [4].

The prevalence of $\mathrm{KC}$ appears to be increasing around the world with an often quoted US study published in 1982 reporting a prevalence of KC of 1:2000 [5]. However, a more recent study in 2017 based on findings from a Dutch health provider reported a $\mathrm{KC}$ prevalence of 1:375 [6]. This rapid and large increase in prevalence most likely reflects our increased ability to detect early changes in $\mathrm{KC}$ through availability of advanced and highly sensitive anterior segment imaging techniques. $\mathrm{KC}$ affects both genders and while a number of studies have indicated a higher preponderance of males with $\mathrm{KC}$ there are still conflicting results on gender predominance [1, 7]. The Collaborative Longitudinal Evaluation of Keratoconus (CLEK) Study investigated $1209 \mathrm{KC}$ patients in the United States and reported a male/female ratio of 1.33 [8]. Godefrooij et al. in the Netherlands and Woodward et al. in the US also reported a higher percentage of males in their $\mathrm{KC}$ patients, with male/female ratio of 1.54 and 1.43 respectively $[6,9]$. Conversely, the studies by Jonas et al. and Hashemi et al. reported opposite results indicating more females with a male/female ratio of 0.29 and 0.58 in India and Tehran, respectively $[10,11]$. In addition, gender differences exist in family history, clinical parameters, symptoms and treatment prognosis in $\mathrm{KC}$ patients $[12,13]$.

$\mathrm{KC}$ is a complex multifactorial condition with both genetic and environmental factors playing a role in its aetiology [14]. Recent studies have made efforts to identify genetic risk factors for $\mathrm{KC}$, but only a small portion of the overall genetic components have been identified. Genetic linkage studies have reported in at least 17 gene loci, indicating the likely presence of multiple genes involved in KC [15]. However, the identification of true diseasecausing genes has been scarce. For the many candidate genes reported to be associated with $\mathrm{KC}$, few of the early detected genes have been replicated [16]. More recently, a genome-wide association study (GWAS) that included samples from Australia, the USA and Northern Ireland identified a putative association of the Hepatocyte growth factor $(H G F)$ gene which, although falling short of genome-wide significance was independently replicated by us $[17,18]$. Further studies to identify causative genes associated with $\mathrm{KC}$ are therefore needed.
One way of identifying causative $\mathrm{KC}$ genes may be through the analysis of genes identified through other complex eye diseases. For example, central corneal thickness (CCT) and increased corneal curvature represent the two main continuous traits observed in KC. Lu et al. [19] were able to demonstrate that of the 27 CCT genes identified through a GWAS for glaucoma, six of these were also associated with CCT in KC. We were able to subsequently replicate 2 of these genes - the MPDZ-NF1B gene and the $B A N P / Z N F 4659$ gene locus in an independent $\mathrm{KC}$ study [20].

In light of the finding that genetic associations identified in one complex eye disease could also be pleiotropic with $\mathrm{KC}$, we further investigated our previous observation of structural posterior segment changes in the eyes of $\mathrm{KC}$ patients [21]. These changes were detected by optical coherence tomography (OCT) and indicated a significantly greater mean retinal thickness in the central fovea, inner and outer macula and increased macular volume compared to non-keratoconus patients. It is currently unknown whether these changes occur as part of $\mathrm{KC}$ disease aetiology or reflect a change in eye dimensions resulting from corneal curvature changes at the anterior segment. Retinal changes also represent a key characteristic in the complex disease age-related macular degeneration (AMD), albeit it from a thinning of the retina. A number of genetic associations with AMD have been identified by the International AMD Gene Consortium in two previous reports [22, 23]. We therefore undertook a case-control genetic association study to investigate the top 19 single nucleotide polymorphisms (SNPs) previously associated with AMD loci reported by Fritsche et al. (2013) to assess their associations with KC on both genders as well as each gender separately, as well as their association with corneal curvature [23].

\section{Methods}

The study protocol was approved by the Royal Victorian Eye and Ear Hospital (RVEEH) Human Research and Ethics Committee (Project\#10/954H). This protocol followed the tenets of the Declaration of Helsinki and all privacy requirements were met.

$\mathrm{KC}$ patients with a European background were recruited from public and private clinics at the RVEEH, private rooms, optometry clinics or consenting general public with $\mathrm{KC}$. A comprehensive eye examination was undertaken for each patient and the diagnostic criteria for $\mathrm{KC}$ has been described in detail elsewhere [18]. Briefly, $\mathrm{KC}$ was diagnosed on the basis of the presence of one or more of the following: [1] an irregular cornea, as determined by distortion of keratometric mires and/ or orbscan/pentacam images, [2] scissoring of the retinoscopic reflex; and [3] demonstration of at least one bio microscopic sign, including Vogt's striae, Fleischer's ring 
or corneal thinning and scarring typical of KC. Potential subjects with non-KC ocular disease in both eyes such as keratectasia, corneal degenerations, macular disease, and optic nerve disease (e.g., optic neuritis, optic atrophy) were excluded from the study.

Non-KC subjects (controls) were recruited from the 'GEnes in Myopia (GEM)' study, where a similar testing protocol was used and has been previously described [24]. Individuals in the GEM study were excluded if they had known ocular disease or insult that could predispose to myopia such as KC. A blood or saliva sample was collected from each subject for subsequent genetic analysis.

\section{SNP selection and genotyping}

Deoxyribonucleic acid (DNA) was extracted from blood or saliva samples using NucleoSpin ${ }^{\circ}$ QuickPure kits and genotyping was performed through the Mass Array platform (Agena Bioscience, San Diego, CA) at the Murdoch Children's Research Institute, Melbourne.

A total of 19 SNPs previously associated with AMD were genotyped. These included rs10490924 (ARMS2/ HTRA1), rs10737680 (CFH), rs13278062 (TNFRSF10A), rs1864163 (CETP), rs2230199 (C3), rs3130783 (IER3/ DDR1), rs334353 (TGFBR1), rs3812111 (COL10A1), rs429608 (C2/CFB), rs4420638 (APOE), rs4698775 (CFI), rs5749482 (TIMP3), rs6795735 (ADAMTS9), rs8017304 (RAD51B), rs8135665 (SLC16A8), rs920915 (LIPC), rs943080 (VEGFA), rs9542236 (B3GALTL) and rs13081855 (COL8A1/FILIP1L) (Additional file 1: Table S1). The SNP rs13081855 was excluded from our analysis due to a low genotyping quality. For each SNP, alleles, genotypes, odd ratio (OR) and 95\% confidence intervals $(95 \% \mathrm{CI})$ were established.

\section{Statistical analysis}

Data were first analysed with RStudio (Version 1.1.456) for Windows. All statistical tests were considered significant when the $p$-value was less than 0.05 . A student's ttest was used to compare age between groups, and a Wilcoxon signed-rank test was applied to test the difference of other clinical characteristics, including corneal curvature, spherical equivalent, axial length and anterior chamber depth.

PLINK v1.07 (http://zzz.bwh.harvard.edu/plink/download.shtml) was applied to perform the following analyses:

1. Logistic regression for testing case/control association with and without covariates (age and gender) adjustment, performed on both genders as well as male and female genders separately;

2. Linear regression for quantitative trait analysis of the selected SNPs for corneal curvature with and without covariate (age) adjustment.
All patients had bilateral eye data, and so only data on right eyes were used for analysis. Bonferroni correction was used to adjust for multiple tests to a level of $p<0.05$.

Power calculations were performed using the online statistical calculator (http://osse.bii.a-star.edu.sg/calculation2.php) with an alpha of 0.05 using a case-control design, based on the minor allele frequency (MAF).

\section{Results}

In total, 614 subjects consisting $248 \mathrm{KC}$ subjects and 366 non-KC subjects were available for analysis. Age and gender were available for all individuals with there being 96 females (38.7\%) in the KC and 232 females (63.4\%) in the non-KC group. The mean age of $\mathrm{KC}$ patients was $35.6 \pm 14.8$ years and non $-K C$ was $48.4 \pm 13.5$ years. The mean age in males and females in $\mathrm{KC}$ was $33.3 \pm 13.5$ and $39.1 \pm 16.0$ years, respectively and in non- KC (controls) was $49.3 \pm 13.3$ and $47.9 \pm 13.6$ years, respectively. $\mathrm{KC}$ patients were significantly younger compared with the non-KC group $(p<0.01)$ and this was the case for both males and females. Demographics for both KC and non-KC are shown (Table 1).

Mean corneal curvature was available for 547 subjects of which 226 out of 248 (91.1\%) were available for the KC group and 321 out of 366 (87.7\%) were available for the non-KC group. $\mathrm{KC}$ patients had a steeper cornea than the non-KC group $(p<0.01)$. Spherical equivalent was available for 517 subjects of which 158 out of 248 $(63.7 \%)$ were available for the $\mathrm{KC}$ group and 359 out of $366(98.1 \%)$ were available for the non-KC group. $\mathrm{KC}$ subjects tended to be more myopic $(p<0.01)$. There was no significant difference in axial length and anterior chamber depth between groups. Clinical characteristics for each group are shown (Table 2).

A total of 18 SNPs were included in the analysis including rs10490924 (ARMS2/HTRA1), rs10737680 (CFH), rs13278062 (TNFRSF10A), rs1864163 (CETP), rs2230199 (C3), rs3130783 (IER3/DDR1), rs334353 (TGFBR1), rs3812111 (COL10A1), rs429608 (C2/CFB), rs4420638 (APOE), rs4698775 (CFI), rs5749482 (TIMP3), rs6795735 (ADAMTS9), rs8017304 (RAD51B), rs8135665 (SLC16A8), rs920915 (LIPC), rs943080 (VEGFA) and rs9542236 (B3GALTL).

Genetic association was performed using logistic regression to evaluate the association of the 18 SNPs with KC. For each SNP, the corrected Bonferroni adjusted $P$ value of $0.05 / 18=2.8 \times 10^{-3}$ was considered statistically significant. Of the $18 \mathrm{SNPs}$, when considering both

Table 1 Demographics for each group

\begin{tabular}{llll}
\hline & $n$ & Mean age (years) (SD) & \% Female \\
\hline KC & 248 & $35.6(14.8)$ & 38.7 \\
Non-KC & 366 & $48.4(13.5)$ & 63.4 \\
\hline
\end{tabular}

$K C=$ keratoconus, $S D=$ standard deviation 
Table 2 Clinical characteristics for each group

\begin{tabular}{lll}
\hline & KC subjects & Non-KC subjects \\
\hline Corneal curvature (D) (SD) & $49.46(7.97)$ & $42.34(2.68)$ \\
Spherical equivalent (D) (SD) & $-4.80(5.22)$ & $-2.63(3.42)$ \\
Axial length (mm) (SD) & $24.38(1.62)$ & $24.65(1.53)$ \\
Anterior chamber depth (mm) (SD) & $3.53(0.58)$ & $3.50(0.39)$ \\
\hline
\end{tabular}

$K C=$ keratoconus, $D=$ Dioptres, $S D=$ standard deviation

genders, only SNP rs6795735 (ADAMTS9) showed a significant association $\left(p=3.5 \times 10^{-4}\right)$ (Table 3$)$. However, the SNP rs5749482 (TIMP3) also showed significant association $\left(p=7.7 \times 10^{-4}\right)$ with $\mathrm{KC}$ when only males were considered in the analysis (Table 4 ). There was no significant association for females. Following the inclusion of age as a covariate (as age was significantly different between $\mathrm{KC}$ and non-KC groups), the associations became non-significant (Tables 3 \& 4).

Linear regression for the quantitative trait analysis of corneal curvature was undertaken for the 18 selected SNPs. There was no significant association for this trait with or without the inclusion of the covariates for age and gender.

\section{Discussion}

Through analysis of the genome-wide significant SNPs originally identified as associated with AMD Fritsche et al. (2013, 23), we were able to confirm that 2 SNPs survived multiple testing in our $\mathrm{KC}$ analysis. These implicated the ADAMTS9 and TIMP3 loci as potentially playing a role in the pathogenesis of $\mathrm{KC}$. We examined the trait of corneal curvature to explore the possibility that these associations were involved in this aspect of $\mathrm{KC}$ disease aetiology but there was limited evidence in their involvement through this mechanism.

The ADAMTS9 (disintegrin and metalloproteinase with thrombospondin motifs 9) gene is a complex secreted enzyme that cleaves large aggregating proteoglycans including aggrecan and versican. It also has a proteaseindependent function in promoting the transport of a variety of secretory items from the endoplasmic reticulum to the Golgi apparatus. It is localized to chromosome 3p14.3-p14.2 and a similar region has been previously implicated in an Italian KC linkage study [25]. The gene is expressed in most eye tissues including the cornea (Ocular Tissue database (https://genome.uiowa.edu)). Other members of the ADAMTS family have previously been implicated in two prior linkage regions reported for $\mathrm{KC}$ with ADAMTS7 identified at chromosome 15q22.33-24.2 and ADAMTS18 at $16 \mathrm{q} 22.3-\mathrm{q} 23.1$ [26, 27]. Interestingly, in both cases, a protease gene was also present in the linked region although no $\mathrm{KC}$ causative gene has yet been identified from either of these linked regions.

Table 3 Logistic regression analysis for the assessment of AMD associated genes with KC in both genders

\begin{tabular}{|c|c|c|c|c|c|c|}
\hline \multirow[b]{2}{*}{ CHR } & \multirow[b]{2}{*}{ SNP } & \multirow[b]{2}{*}{ Minor Allele Name } & \multicolumn{2}{|c|}{ Without adjusting for age $\&$ gender } & \multicolumn{2}{|c|}{ Adjusting for age $\&$ gender } \\
\hline & & & Odds Ratio $(95 \% \mathrm{Cl})$ & $P$ & Odds Ratio $(95 \% \mathrm{Cl})$ & $P$ \\
\hline 3 & rs6795735 & $\mathrm{T}$ & $1.52(1.21-1.92)$ & $3.5 \times 10^{-4}$ & $1.35(1.04-1.75)$ & $2.2 \times 10^{-2}$ \\
\hline 22 & rs5749482 & C & $1.53(1.13-2.09)$ & $6.6 \times 10^{-3}$ & $1.28(0.90-1.82)$ & $1.7 \times 10^{-1}$ \\
\hline 13 & rs9542236 & C & $0.73(0.58-0.92)$ & $7.8 \times 10^{-3}$ & $0.82(0.64-1.07)$ & $1.4 \times 10^{-1}$ \\
\hline 10 & rs10490924 & $\mathrm{T}$ & $1.34(1.03-1.76)$ & $3.1 \times 10^{-2}$ & $1.27(0.94-1.72)$ & $1.2 \times 10^{-1}$ \\
\hline 6 & rs943080 & C & $0.79(0.63-0.99)$ & $4.0 \times 10^{-2}$ & $0.91(0.70-1.17)$ & $4.4 \times 10^{-1}$ \\
\hline 19 & rs2230199 & G & $0.79(0.58-1.07)$ & $1.2 \times 10^{-1}$ & $0.77(0.55-1.09)$ & $1.4 \times 10^{-1}$ \\
\hline 6 & rs429608 & A & $1.25(0.92-1.70)$ & $1.5 \times 10^{-1}$ & $1.33(0.94-1.88)$ & $1.1 \times 10^{-1}$ \\
\hline 16 & rs1864163 & A & $0.82(0.63-1.08)$ & $1.5 \times 10^{-1}$ & $0.95(0.70-1.28)$ & $7.1 \times 10^{-1}$ \\
\hline 4 & rs4698775 & G & $1.20(0.93-1.55)$ & $1.6 \times 10^{-1}$ & $1.27(0.95-1.69)$ & $1.0 \times 10^{-1}$ \\
\hline 15 & rs920915 & C & $0.85(0.68-1.07)$ & $1.7 \times 10^{-1}$ & $0.89(0.69-1.16)$ & $3.8 \times 10^{-1}$ \\
\hline 1 & rs 10737680 & $C$ & $1.14(0.91-1.43)$ & $2.6 \times 10^{-1}$ & $1.02(0.79-1.32)$ & $8.7 \times 10^{-1}$ \\
\hline 6 & rs3812111 & A & $0.88(0.70-1.11)$ & $2.7 \times 10^{-1}$ & $0.82(0.63-1.06)$ & $1.3 \times 10^{-1}$ \\
\hline 8 & rs13278062 & G & $0.90(0.72-1.13)$ & $3.7 \times 10^{-1}$ & $0.89(0.70-1.15)$ & $3.8 \times 10^{-1}$ \\
\hline 14 & rs8017304 & G & $1.11(0.88-1.39)$ & $3.9 \times 10^{-1}$ & $1.06(0.82-1.37)$ & $6.5 \times 10^{-1}$ \\
\hline 6 & rs3130783 & G & $0.90(0.68-1.19)$ & $4.7 \times 10^{-1}$ & $0.93(0.68-1.26)$ & $6.3 \times 10^{-1}$ \\
\hline 19 & rs4420638 & G & $0.91(0.68-1.21)$ & $5.1 \times 10^{-1}$ & $0.83(0.60-1.16)$ & $2.7 \times 10^{-1}$ \\
\hline 22 & rs8135665 & A & $1.08(0.81-1.45)$ & $6.0 \times 10^{-1}$ & $1.28(0.92-1.79)$ & $1.4 \times 10^{-1}$ \\
\hline 9 & rs334353 & G & $0.97(0.75-1.25)$ & $8.0 \times 10^{-1}$ & $1.00(0.75-1.34)$ & $9.8 \times 10^{-1}$ \\
\hline
\end{tabular}

$A M D=$ age-related macular degeneration, $K C=$ keratoconus, $C l=$ confidence intervals, $C H R=$ chromosome, $S N P=$ single nucleotide polymorphisms

$P$ value for statistical significance is $0.05 / 18=2.8 \times 10^{-3}$

Bolded value indicates significance

$95 \% \mathrm{Cl}-95 \%$ confidence interval 
Table 4 Logistic regression analysis for the assessment of AMD associated genes with KC in males

\begin{tabular}{|c|c|c|c|c|c|c|}
\hline \multirow[b]{2}{*}{ CHR } & \multirow[b]{2}{*}{ SNP } & \multirow[b]{2}{*}{ Minor Allele Name } & \multicolumn{2}{|c|}{ Without age adjustment } & \multicolumn{2}{|l|}{ Adjusting for age } \\
\hline & & & Odds Ratio $(95 \% \mathrm{Cl})$ & $P$ & Odds Ratio (95\% Cl) & $P$ \\
\hline 22 & rs5749482 & C & $2.29(1.41-3.71)$ & $7.7 \times 10^{-4}$ & $1.76(1.01-3.08)$ & $4.8 \times 10^{-2}$ \\
\hline 3 & rs6795735 & $\mathrm{T}$ & $1.60(1.15-2.23)$ & $5.4 \times 10^{-3}$ & $1.36(0.93-1.99)$ & $1.1 \times 10^{-1}$ \\
\hline 6 & rs943080 & C & $0.68(0.50-0.94)$ & $1.9 \times 10^{-2}$ & $0.75(0.52-1.09)$ & $1.4 \times 10^{-1}$ \\
\hline 13 & rs9542236 & C & $0.72(0.52-1.00)$ & $4.8 \times 10^{-2}$ & $0.97(0.66-1.42)$ & $8.7 \times 10^{-1}$ \\
\hline 10 & rs10490924 & $\mathrm{T}$ & $1.44(0.99-2.10)$ & $5.7 \times 10^{-2}$ & $1.54(0.99-2.40)$ & $5.4 \times 10^{-2}$ \\
\hline 6 & rs429608 & A & $1.49(0.95-2.34)$ & $7.9 \times 10^{-2}$ & $1.77(1.05-2.99)$ & $3.1 \times 10^{-2}$ \\
\hline 15 & rs920915 & C & $0.75(0.54-1.05)$ & $8.9 \times 10^{-2}$ & $0.82(0.56-1.21)$ & $3.2 \times 10^{-1}$ \\
\hline 14 & rs8017304 & G & $1.31(0.93-1.85)$ & $1.2 \times 10^{-1}$ & $1.31(0.88-1.96)$ & $1.9 \times 10^{-1}$ \\
\hline 9 & rs334353 & G & $0.85(0.59-1.23)$ & $4.0 \times 10^{-1}$ & $0.91(0.59-1.39)$ & $6.6 \times 10^{-1}$ \\
\hline 8 & rs13278062 & G & $0.88(0.64-1.23)$ & $4.6 \times 10^{-1}$ & $0.85(0.58-1.25)$ & $4.1 \times 10^{-1}$ \\
\hline 16 & rs1864163 & A & $0.86(0.57-1.29)$ & $4.6 \times 10^{-1}$ & $0.92(0.58-1.47)$ & $7.4 \times 10^{-1}$ \\
\hline 6 & rs3812111 & A & $0.89(0.64-1.24)$ & $4.9 \times 10^{-1}$ & $0.81(0.55-1.19)$ & $2.8 \times 10^{-1}$ \\
\hline 19 & rs2230199 & G & $0.88(0.58-1.33)$ & $5.4 \times 10^{-1}$ & $1.05(0.65-1.71)$ & $8.3 \times 10^{-1}$ \\
\hline 22 & rs8135665 & A & $1.09(0.73-1.63)$ & $6.6 \times 10^{-1}$ & $1.35(0.85-2.17)$ & $2.1 \times 10^{-1}$ \\
\hline 4 & rs4698775 & G & $0.96(0.67-1.37)$ & $8.2 \times 10^{-1}$ & $1.05(0.69-1.60)$ & $8.3 \times 10^{-1}$ \\
\hline 19 & rs4420638 & G & $1.05(0.70-1.57)$ & $8.3 \times 10^{-1}$ & $0.90(0.56-1.46)$ & $6.8 \times 10^{-1}$ \\
\hline 6 & rs3130783 & G & $0.98(0.66-1.45)$ & $9.1 \times 10^{-1}$ & $1.10(0.69-1.75)$ & $7.0 \times 10^{-1}$ \\
\hline 1 & rs10737680 & C & $1.01(0.72-1.42)$ & $9.6 \times 10^{-1}$ & $0.78(0.52-1.17)$ & $2.2 \times 10^{-1}$ \\
\hline
\end{tabular}

$A M D=$ age-related macular degeneration, $K C=$ keratoconus, $C H R=$ chromosome, $C l=$ confidence intervals, $S N P=$ single nucleotide polymorphisms

$P$ value for statistical significance is $0.05 / 18=2.8 \times 10^{-3}$

Bolded value indicates significance

$95 \% \mathrm{Cl}-95 \%$ confidence interval

TIMP3 is a member of the TIMP (tissue inhibitors of metalloproteinases) family which represents a group of peptidases involved in the degradation of the ECM (extracellular matrix). Expression of this gene is induced in response to mitogenic stimulation and the protein is localized to the ECM. It is highly expressed in the cornea (Ocular Tissue database (https://genome.uiowa.edu)) and a previous study has indicated that differential gene expression showed a 14-fold decrease in expression of this gene in $\mathrm{KC}$ in cultured corneal stromal fibroblasts when comparing $\mathrm{KC}$ and non- $\mathrm{KC}$ controls [28]. In contrast, a previous study by De Bonis et al. did not find any specific mutations or novel variants in this gene in 302 Italian KC patients following the sequencing of its coding regions and they therefore ruled it out as being involved in $\mathrm{KC}$ [29]. Interestingly another member of the TIMP family (TIMP1) has also been implicated in $\mathrm{KC}$ where a significant reduction in both transcript level $(p<0.05)$ and protein $(p<0.0001)$ were reported [30]. Additionally, the SNP rs6609533 in TIMP-1 was also reported as being associated with $\mathrm{KC}$ (OR 2.27, 95\% CI, 1.06-4.76, $P=0.036)$ when comparing $140 \mathrm{KC}$ patients and 150 healthy controls [31]. These findings suggest an increasing body of evidence for a role of TIMP genes in $\mathrm{KC}$ and more broadly speaking, the likely role of genes involved in the ECM as having some involvement in KC.
Our study also investigated the association of AMDrelated genes with $\mathrm{KC}$ in females and males separately. Gender differences have been reported in $\mathrm{KC}$, differing in terms of prevalence, clinical parameters, symptoms and treatment prognosis. Males present at a higher prevalence in most studies, and the present study showed the same trend, with $61.3 \%$ of the $\mathrm{KC}$ group being male $[12,13]$. We also noted that the TIMP3 gene appeared to show association only when males were considered whereas no sex-specific associations were noted with females. This therefore begs the question as to whether there are sexspecific genetic associations in $\mathrm{KC}$ which might therefore contribute to disease aetiology. However, this finding could also reflect that in the current study, there were more males than females and thus the significant associations observed in male cases could be related to this larger sample size.

In our analysis, we included a group of individuals without $\mathrm{KC}$ as our control group which was deliberately chosen to be older than the $\mathrm{KC}$ group to exclude or minimize the possibility of the occurrence of any $\mathrm{KC}$. In undertaking our analysis, we included a co-variate of age in our analysis but the significant genetic associations for both the TIMP3 and ADAMTS9 genes disappeared. This questions whether the associations we have identified are true associations or perhaps represent allelic 
differences which might be age dependent. In a previous study of SNPs associated with AMD, we were able to show that different genotype frequencies were seen across different 10-year age groups for several SNPs (rs1061170 (Y402H), rs2274700, rs393955) in the complement factor $\mathrm{H}(\mathrm{CFH})$ gene, albeit at an older age. These different genotype frequencies occurred across the age range of 48-86 years where the prevalence of the low-risk homozygote rose with each increasing age group [32]. However, not all tested SNPs in that study showed an age-dependent change with SNP rs800292 in the $C F H$ gene not being significant [32]. In addition, not all known AMD associated SNPs were examined for age differences in that study and thus there are no known reports of genotype frequencies varying with age for the majority of the currently assessed AMD SNPs.

As a further analysis in our current study, we grouped all $\mathrm{KC}$ cases and controls together and then split them into tertiles. The upper age tertile group (range 52 to 87 years) and lower tertile group (age range 5 to 34 years) consisted of 211 and 204 individuals separately and were compared for an age effect. Interestingly, for both rs6795735 and rs5749482, significant associations $\left(p=2 \times 10^{-2}\right.$ and $p=$ $2 \times 10^{-3}$, respectively) were identified between the two tertiles groups. While $\mathrm{KC}$ has typically been reported as developing at an early age, we did not expect to find an age effect in our KC study for the reported SNPs. The selfreported average age of $\mathrm{KC}$ onset typically ranges from 16.7 to 28.3 years, centering in the second or third decade of a patient's life [6, 33-35]. However, the youngest-described $\mathrm{KC}$ patient in 2015 has been reported as only being four years old [36]. Furthermore, assessment of older KC patients has reported that the number of patients older than 50 years with $\mathrm{KC}$ is higher than before [37].

Power calculations for SNP rs6795735 (ADAMTS9) (minor allele frequency 0.52 in cases and 0.41 in controls) indicated $77 \%$ power to detect significant association when both genders were used. In the case of SNP rs5749482 (TIMP3) with a minor allele frequency of 0.19 in cases and 0.13 in controls, our study had $51.2 \%$ power to detect significant association when both genders were included. Subsequently, power would be expected to decrease if males and females were considered in separate analyses. However, in the case of SNP s5749482, power actually increased to $73 \%$ for a male only analysis but diminished to only $4.2 \%$ in a female only analysis. This reflected differences in allele frequencies between males and females for this SNP being 0.21 in $\mathrm{KC}$ cases and 0.10 in controls (males) but 0.16 in $\mathrm{KC}$ and 0.15 in controls (females). To obtain an appropriate sample size to be well powered at this SNP in females would require 17,136 KC cases and 25,704 controls. Clearly, this scenario would be highly unlikely to be achieved given the paucity of $\mathrm{KC}$ samples but does present an important limitation in assessment of gender differences when undertaking genetic associations. Given that $\mathrm{KC}$ is a relatively rare condition, the majority of DNA studies in $\mathrm{KC}$ typically have a small sample size (approximately 200 cases and 300 control subjects). Thus, the number of subjects in the present study are comparable with other studies but does raise an important issue in allele frequency differences that may exist between males and females as well as between individuals of different ethnicities. Another consideration in this study was age. While $\mathrm{KC}$ is not classified as an agerelated disease due to its relatively early age of onset, there is a likelihood that older controls will be used as a comparison group to minimize the potential inclusion of incident KC. However, if a SNP exhibits differences in allele frequency with age then this must also be considered. Further studies are needed to resolve these issues, by performing genetic association tests between age-and gender matched groups to minimize any effects of age or sex. Ultimately, this will require very large samples sizes to address such issues which may be impossible to achieve in a relatively uncommon condition such as KC.

\section{Conclusions}

$\mathrm{KC}$ is a complex condition where genetics appear to play a vital role [38, 39]. While many candidate genes and linkage regions have been identified in $\mathrm{KC}$ through previous twin/family and case-control studies, few genes have been consistently reported [17-20,31, 40-86]. Given our previous observation of posterior segment changes in the eye of $\mathrm{KC}$ patients [21], we sought to assess whether genes implicated in the complex eye disease of AMD may also show some involvement in KC. While the data are suggestive, given that at least 2 SNPs survive multiple correction, their involvement in this disease is not confirmed as it appears that these associations can be influenced by age and gender co-variates. These observations may explain the lack of reproducibility in different $\mathrm{KC}$ studies depending on methodology but if it can be demonstrated that such associations do exist in larger or replicated cohorts then this would open new avenues for the involvement of genes involved in the $\mathrm{KC}$ disease pathway. Ultimately, the likely resolution to the answer of the suggested genetic associations described in this study as well as prior studies will most likely arise through undertaking a large scale GWAS for $\mathrm{KC}$ as this will identify genes in a hypothesisfree manner in a larger patient population.

\section{Supplementary information}

Supplementary information accompanies this paper at https://doi.org/10. 1186/s40662-019-0164-z.

Additional file 1: Table S1. Full names of genes studied in the present study. The table shows the full names of genes studied in the present study 


\section{Abbreviations}

AMD: Age-related macular degeneration; CCT: Central corneal thickness; Cl: Confidence intervals; CLEK: Collaborative Longitudinal Evaluation of Keratoconus; CXL: Corneal collagen cross-linking; DNA: Deoxyribonucleic acid; ECM: Extracellular matrix; GEM: GEnes in Myopia; GWAS: Genome wide association studies; HGF: Hepatocyte growth factor; KC: Keratoconus; MAF: Minor allele frequency; OCT: Optical coherence tomography; OR: Odd ratio; RVEEH: Royal Victorian Eye and Ear Hospital; SNPs: Single nucleotide polymorphisms; TIMP: Tissue inhibitors of metalloproteinases

\section{Acknowledgements}

The authors wish to thank all participants who took part in this Keratoconus study and made this work possible. The authors would also like to thank Eye Surgery Associates, Lindsay and Associates and Keratoconus Australia, as well as Mr. Tony Ngo for assistance with subject recruitment.

\section{Authors' contributions}

KC performed all the analysis and wrote the manuscript. SS collected patient data and was involved in reviewing and writing of the manuscript. PB guided all analyses and involved in writing and reviewing the manuscript. AR genotyped the SNPs involved in this study. All authors read and approved the final manuscript.

\section{Funding}

This study was supported by the Australian National Health and Medical Research Council (NHMRC) project grant GNT1104700 and Senior Research Fellowship (1138585 to PN Baird), the Angior Family Foundation and a Lions Eye Foundation Fellowship (SS). The Centre for Eye Research Australia (CERA) receives Operational Infrastructure Support from the Victorian Government.

\section{Availability of data and materials}

The datasets used and/or analysed during the current study are available from the corresponding author (Paul Baird) on reasonable request.

\section{Ethics approval and consent to participate}

The study protocol was approved by the Royal Victorian Eye and Ear Hospital (RVEEH) Human Research and Ethics Committee (Project\#10/954H). This protocol followed the tenets of the Declaration of Helsinki and all privacy requirements were met. Written informed consent was obtained from each participant.

\section{Consent for publication}

All listed authors have provided consent for publication of this article.

\section{Competing interests}

The authors declare that they have no competing interests.

\section{Author details}

${ }^{1}$ Centre for Eye Research Australia, Royal Victorian Eye and Ear Hospital, Melbourne, Australia. ${ }^{2}$ Department of Surgery, Ophthalmology, The University of Melbourne, 32 Gisborne Street, East Melbourne, VIC 3000, Australia.

Received: 14 June 2019 Accepted: 3 November 2019

Published online: 01 December 2019

\section{References}

1. Gordon-Shaag A, Millodot M, Shneor E, Liu Y. The genetic and environmental factors for keratoconus. Biomed Res Int. 2015;2015:795738.

2. Williams KA, Keane MC, Galettis RA, Mills RA Jones VJ, Coster DJ, The Australian Corneal Graft Registry, issuing body, Australian Organ and Tissue Donation and Transplantation Authority. The Australian corneal graft registry: 2018 report. 2018. Retrieved June 3, 2019, from http://nla.gov.au/nla.obj-726934474.

3. Jhanji V, Sharma N, Vajpayee RB. Management of keratoconus: current scenario. Br J Ophthalmol. 2011;95(8):1044-50.

4. Bykhovskaya Y, Gromova A, Makarenkova HP, Rabinowitz YS. Abnormal regulation of extracellular matrix and adhesion molecules in corneas of patients with keratoconus. Int J Keratoconus Ectatic Corneal Dis. 2016; 5(2):63-70.

5. Kennedy RH, Bourne WM, Dyer JA. A 48-year clinical and epidemiologic study of keratoconus. Am J Ophthalmol. 1986;101(3):267-73.
6. Godefrooij DA, de Wit GA, Uiterwaal CS, Imhof SM, Wisse RP. Age-specific incidence and prevalence of keratoconus: a nationwide registration study. Am J Ophthalmol. 2017;175:169-72.

7. Sharif R, Bak-Nielsen S, Hjortdal J, Karamichos D. Pathogenesis of keratoconus: the intriguing therapeutic potential of prolactin-inducible protein. Prog Retin Eye Res. 2018;67:150-67.

8. Wagner H, Barr JT, Zadnik K. Collaborative Longitudinal Evaluation of Keratoconus (CLEK) Study: methods and findings to date. Cont Lens Anterior Eye. 2007;30(4):223-32.

9. Woodward MA, Blachley TS, Stein JD. The association between sociodemographic factors, common systemic diseases, and keratoconus: an analysis of a nationwide heath care claims database. Ophthalmology. 2016; 123(3):457-65.e2

10. Jonas JB, Nangia V, Matin A, Kulkarni M, Bhojwani K. Prevalence and associations of keratoconus in rural Maharashtra in central India: the central India eye and medical study. Am J Ophthalmol. 2009;148(5):760-5.

11. Hashemi H, Beiranvand A, Khabazkhoob M, Asgari S, Emamian MH, Shariati $\mathrm{M}$, et al. Prevalence of keratoconus in a population-based study in Shahroud. Cornea. 2013:32(11):1441-5.

12. Magalhaes OA, Marafon SB, Ferreira RC. Gender differences in keratoconus keratoplasty: a 25-year study in southern Brazil and global perspective. Int Ophthalmol. 2018;38(4):1627-33.

13. Fink BA, Wagner H, Steger-May K, Rosenstiel C, Roediger T, McMahon $T$, et al. Differences in keratoconus as a function of gender. Am J Ophthalmol. 2005;140(3):459-68.

14. Davidson AE, Hayes S, Hardcastle AJ, Tuft SJ. The pathogenesis of keratoconus. Eye (Lond). 2014;28(2):189-95.

15. Burdon KP, Vincent AL. Insights into keratoconus from a genetic perspective. Clin Exp Optom. 2013;96(2):146-54.

16. Bykhovskaya Y, Margines B, Rabinowitz YS. Genetics in Keratoconus: where are we? Eye Vis (Lond). 2016;3:16. https://doi.org/10.1186/s40662-016-0047-5.

17. Burdon KP, Macgregor S, Bykhovskaya Y, Javadiyan S, Li X, Laurie KJ, et al. Association of polymorphisms in the hepatocyte growth factor gene promoter with keratoconus. Invest Ophthalmol Vis Sci. 2011;52(11):8514-9.

18. Sahebjada S, Schache M, Richardson AJ, Snibson G, Daniell M, Baird PN. Association of the hepatocyte growth factor gene with keratoconus in an Australian population. PLoS One. 2014;9(1):e84067.

19. Lu Y, Vitart V, Burdon KP, Khor CC, Bykhovskaya Y, Mirshahi A, et al. Genome-wide association analyses identify multiple loci associated with central corneal thickness and keratoconus. Nat Genet. 2013;45(2):155-63.

20. Sahebjada S, Schache M, Richardson AJ, Snibson G, MacGregor S, Daniell M, et al. Evaluating the association between keratoconus and the corneal thickness genes in an independent Australian population. Invest Ophthalmol Vis Sci. 2013;54(13):8224-8.

21. Sahebjada S, Amirul Islam FM, Wickremasinghe S, Daniell M, Baird PN. Assessment of macular parameter changes in patients with keratoconus using optical coherence tomography. J Ophthalmol. 2015;2015:245953.

22. Fritsche LG, Ig| W, Bailey JN, Grassmann F, Sengupta S, Bragg-Gresham JL, et al. A large genome-wide association study of age-related macular degeneration highlights contributions of rare and common variants. Nat Genet. 2016;48(2):134-43.

23. Fritsche LG, Chen W, Schu M, Yaspan BL, Yu Y, Thorleifsson G, et al. Seven new loci associated with age-related macular degeneration. Nat Genet. 2013:45(4):433-9, 439e1-2.

24. Garoufalis $\mathrm{P}, \mathrm{Chen} C \mathrm{CY}$, Dirani M, Couper TA, Taylor HR, Baird PN. Methodology and recruitment of probands and their families for the Genes in Myopia (GEM) Study. Ophthalmic Epidemiol. 2005;12(6):383-92.

25. Brancati F, Valente EM, Sarkozy A, Fehèr J, Castori M, Del Duca P, et al. A locus for autosomal dominant keratoconus maps to human chromosome 3p14-q13. J Med Genet. 2004;41(3):188-92.

26. Dash DP, Silvestri $G$, Hughes AE. Fine mapping of the keratoconus with cataract locus on chromosome $15 q$ and candidate gene analysis. Mol Vis. 2006;12:499-505.

27. Tyynismaa $H$, Sistonen $P$, Tuupanen $S$, Tervo $T$, Dammert $A$, Latvala $T$, et al. A locus for autosomal dominant keratoconus: linkage to $16 q 22.3-q 23.1$ in Finnish families. Invest Ophthalmol Vis Sci. 2002:43(10):3160-4.

28. Lee JE, Oum BS, Choi HY, Lee SU, Lee JS. Evaluation of differentially expressed genes identified in keratoconus. Mol Vis. 2009;15:2480-7.

29. De Bonis P, Laborante A, Pizzicoli C, Stallone R, Barbano R, Longo C, et al. Mutational screening of VSX1, SPARC, SOD1, LOX and TIMP3 in keratoconus. Mol Vis. 2011;17:2482-94. 
30. Kenney MC, Chwa M, Atilano SR, Tran A, Carballo M, Saghizadeh M, et al Increased levels of catalase and cathepsin V/L2 but decreased TIMP-1 in keratoconus corneas: evidence that oxidative stress plays a role in this disorder. Invest Ophthalmol Vis Sci. 2005;46(3):823-32.

31. Saravani R, Yari D, Saravani S, Hasanian-Langroudi F. Correlation between the COL4A3, MMP-9, and TIMP-1 polymorphisms and risk of keratoconus. Jpn J Ophthalmol. 2017;61(3):218-22.

32. Adams MK, Simpson JA, Richardson AJ, Guymer RH, Williamson E, Cantsilieris S, et al. Can genetic associations change with age? CFH and age-related macular degeneration. Hum Mol Genet. 2012;21(23):5229-36.

33. Li X, Rabinowitz YS, Rasheed K, Yang H. Longitudinal study of the normal eyes in unilateral keratoconus patients. Ophthalmology. 2004;111(3):440-6.

34. Millodot M, Ortenberg I, Lahav-Yacouel K, Behrman S. Effect of ageing on keratoconic corneas. J Optom. 2016;9(2):72-7.

35. Olivares Jiménez $J \mathrm{~L}$, Guerrero Jurado JC, Bermudez Rodriguez FJ, Serrano Laborda D. Keratoconus: age of onset and natural history. Optom Vis Sci. 1997;74(3):147-51.

36. Sabti S, Tappeiner C, Frueh BE. Corneal cross-linking in a 4-year-old child with keratoconus and Down syndrome. Cornea. 2015;34(9):1157-60.

37. Yildiz EH, Diehl GF, Cohen EJ, Hammersmith KM, Laibson PR, Rapuano CJ. Demographics of patients older than 50 years with keratoconus. Eye Contact Lens. 2009;35(6):309-11.

38. Chang HY, Chodosh J. The genetics of keratoconus. Semin Ophthalmol. 2013;28(5-6):275-80

39. Tuft SJ, Hassan H, George S, Frazer DG, Willoughby CE, Liskova P. Keratoconus in 18 pairs of twins. Acta Ophthalmol. 2012;90(6):e482-6.

40. Bykhovskaya Y, Li X, Epifantseva I, Haritunians T, Siscovick D, Aldave A, et al. Variation in the lysyl oxidase (LOX) gene is associated with keratoconus in family-based and case-control studies. Invest Ophthalmol Vis Sci. 2012;53(7): 4152-7.

41. Dudakova L, Palos M, Jirsova K, Stranecky V, Krepelova A, Hysi PG, et al. Validation of rs2956540:G>C and rs3735520:G>A association with keratoconus in a population of European descent. Eur J Hum Genet. 2015; 23(11):1581-3.

42. Li X, Bykhovskaya Y, Canedo AL, Haritunians T, Siscovick D, Aldave AJ, et al. Genetic association of COL5A1 variants in keratoconus patients suggests a complex connection between corneal thinning and keratoconus. Invest Ophthalmol Vis Sci. 2013;54(4):2696-704.

43. Liskova P, Dudakova L, Krepelova A, Klema J, Hysi PG. Replication of SNP associations with keratoconus in a Czech cohort. PLoS One. 2017;12(2): e0172365.

44. Synowiec E, Wojcik KA, Izdebska J, Binczyk E, Blasiak J, Szaflik J, et al. Polymorphisms of the homologous recombination gene RAD51 in keratoconus and Fuchs endothelial corneal dystrophy. Dis Markers. 2013; 35(5):353-62.

45. Synowiec E, Wojcik KA, Izdebska J, Binczyk E, Szaflik J, Blasiak J, et al. Polymorphism of the LIG3 gene in keratoconus and Fuchs endothelial corneal dystrophy. Cell Mol Biol (Noisy-le-grand). 2015;61(1):56-63.

46. Wojcik KA, Synowiec E, Sobierajczyk K, Izdebska J, Blasiak J, Szaflik J, et al. Polymorphism of the DNA base excision repair genes in keratoconus. Int J Mol Sci. 2014;15(11):19682-99.

47. Bisceglia L, Ciaschetti M, De Bonis P, Campo PA, Pizzicoli C, Scala C, et al. VSX1 mutational analysis in a series of Italian patients affected by keratoconus: detection of a novel mutation. Invest Ophthalmol Vis Sci. 2005; 46(1):39-45.

48. Karolak JA, Polakowski P, Szaflik J, Szaflik JP, Gajecka M. Molecular screening of keratoconus susceptibility sequence variants in VSX1, TGFBI, DOCK9, STK24, and IPO5 genes in Polish patients and novel TGFBI variant identification. Ophthalmic Genet. 2016;37(1):37-43.

49. Li X, Bykhovskaya Y, Tang YG, Picornell Y, Haritunians T, Aldave AJ, et al. An association between the calpastatin (CAST) gene and keratoconus. Cornea. 2013;32(5):696-701.

50. Moschos MM, Kokolakis N, Gazouli M, Chatziralli IP, Droutsas D, Anagnou NP, et al. Polymorphism analysis of VSX1 and SOD1 genes in Greek patients with keratoconus. Ophthalmic Genet. 2015;36(3):213-7.

51. Nowak DM, Karolak JA, Kubiak J, Gut M, Pitarque JA, Molinari A, et al. Substitution at IL1RN and deletion at SLC4A11 segregating with phenotype in familial keratoconus. Invest Ophthalmol Vis Sci. 2013;54(3):2207-15.

52. Stabuc-Silih M, Ravnik-Glavac M, Glavac D, Hawlina M, Strazisar M. Polymorphisms in COL4A3 and COL4A4 genes associated with keratoconus. Mol Vis. 2009;15:2848-60.
53. Stabuc-Silih M, Strazisar M, Ravnik-Glavac M, Hawlina M, Glavac D. Genetics and clinical characteristics of keratoconus. Acta Dermatovenerol Alp Pannonica Adriat. 2010;19(2):3-10.

54. Wojcik KA, Synowiec E, Kaminska A, Izdebska J, Polakowski P, Pawlowska E, et al. Polymorphism of the APEX nuclease 1 gene in keratoconus and Fuchs endothelial corneal dystrophy. Cell Mol Biol Lett. 2015;20(1):48-65.

55. Wojcik KA, Synowiec E, Polakowski P, Glowacki S, Izdebska J, Lloyd S, et al. Polymorphism of the flap endonuclease 1 gene in keratoconus and Fuchs endothelial corneal dystrophy. Int J Mol Sci. 2014;15(8):14786-802.

56. Lechner J, Porter LF, Rice A, Vitart V, Armstrong DJ, Schorderet DF, et al. Enrichment of pathogenic alleles in the brittle cornea gene, ZNF469, in keratoconus. Hum Mol Genet. 2014;23(20):5527-35.

57. Moschos MM, Droutsas K, Sioziou A, Dettoraki M, Gazouli M. Mutational analysis of pre-miR-184 and hsa-mir-568 in Greek patients with sporadic keratoconus. Cornea. 2016:35(5):631-3.

58. Stabuc-Silih M, Strazisar M, Hawlina M, Glavac D. Absence of pathogenic mutations in VSX1 and SOD1 genes in patients with keratoconus. Cornea. 2010;29(2):172-6.

59. Synowiec E, Wojcik KA, Izdebska J, Blasiak J, Szaflik J, Szaflik JP. Polymorphisms of the apoptosis-related FAS and FAS ligand genes in keratoconus and Fuchs endothelial corneal dystrophy. Tohoku J Exp Med. 2014;234(1):17-27.

60. Wójcik KA, Synowiec E, Jiménez-García MP, Kaminska A, Polakowski P, Blasiak J, et al. Polymorphism of the transferrin gene in eye diseases: keratoconus and Fuchs endothelial corneal dystrophy. Biomed Res Int. 2013;2013:247438.

61. Bae HA, Mills RA, Lindsay RG, Phillips T, Coster DJ, Mitchell P, et al. Replication and meta-analysis of candidate loci identified variation at RAB3GAP1 associated with keratoconus. Invest Ophthalmol Vis Sci. 2013; 54(7):5132-5.

62. Bardak H, Gunay M, Yildiz E, Bardak Y, Gunay B, Ozbas H, et al. Novel visual system homeobox 1 gene mutations in Turkish patients with keratoconus. Genet Mol Res. 2016;15(4). https://doi.org/10.4238/gmr15049024.

63. Hao XD, Chen P, Chen ZL, Li SX, Wang Y. Evaluating the association between keratoconus and reported genetic loci in a Han Chinese population. Ophthalmic Genet. 2015;36(2):132-6.

64. Mikami T, Meguro A, Teshigawara T, Takeuchi M, Uemoto R, Kawagoe T, et al. Interleukin 1 beta promoter polymorphism is associated with keratoconus in a Japanese population. Mol Vis. 2013;19:845-51.

65. Wang $Y$, Jin T, Zhang X, Wei W, Cui Y, Geng T, et al. Common single nucleotide polymorphisms and keratoconus in the Han Chinese population. Ophthalmic Genet. 2013;34(3):160-6.

66. Wang Y, Wei W, Zhang C, Zhang X, Liu M, Zhu X, et al. Association of interleukin-1 gene single nucleotide polymorphisms with keratoconus in Chinese Han population. Curr Eye Res. 2016;41(5):630-5.

67. Zhang J, Wu D, Li Y, Fan Y, Chen H, Xu J. Evaluating the association between calpastatin (CAST) gene and keratoconus in the Han Chinese population. Gene. 2018;653:10-3.

68. Guan T, Wang X, Zheng LB, Wu HJ, Yao YF. Analysis of the VSX1 gene in sporadic keratoconus patients from China. BMC Ophthalmol. 2017;17(1):173.

69. Guan T, Wu HJ, Zhang LJ, Xu DJ, Zheng LB, Yao YF. A novel VSX1 gene mutation identified in a sporadic keratoconus patient from China. Zhonghua Yan Ke Za Zhi. 2018;54(3):212-7.

70. Kim SH, Mok JW, Kim HS, Joo CK. Association of $-31 \mathrm{~T}>\mathrm{C}$ and $-511 \mathrm{C}>\mathrm{T}$ polymorphisms in the interleukin 1 beta (IL1B) promoter in Korean keratoconus patients. Mol Vis. 2008;14:2109-16.

71. Mok JW, Baek SJ, Joo CK. VSX1 gene variants are associated with keratoconus in unrelated Korean patients. J Hum Genet. 2008;53(9):842-9.

72. Paliwal P, Singh A, Tandon R, Titiyal JS, Sharma A. A novel VSX1 mutation identified in an individual with keratoconus in India. Mol Vis. 2009;15:2475-9.

73. Cuellar-Partida G, Springelkamp H, Lucas SE, Yazar S, Hewitt AW, Iglesias Al, et al. WNT10A exonic variant increases the risk of keratoconus by decreasing corneal thickness. Hum Mol Genet. 2015;24(17):5060-8.

74. Hao XD, Chen P, Zhang YY, Li SX, Shi WY, Gao H. De novo mutations of TUBA3D are associated with keratoconus. Sci Rep. 2017;7(1):13570.

75. Saee-Rad S, Hashemi H, Miraftab M, Noori-Daloii MR, Chaleshtori MH, Raoofian R, et al. Mutation analysis of VSX1 and SOD1 in Iranian patients with keratoconus. Mol Vis. 2011;17:3128-36.

76. Shetty R, Nuijts RM, Nanaiah SG, Anandula VR, Ghosh A, Jayadev C, et al. Two novel missense substitutions in the VSX1 gene: clinical and genetic analysis of families with Keratoconus from India. BMC Med Genet. 2015;16:33. 
77. Vincent AL, Jordan CA, Cadzow MJ, Merriman TR, McGhee CN. Mutations in the zinc finger protein gene, ZNF469, contribute to the pathogenesis of keratoconus. Invest Ophthalmol Vis Sci. 2014;55(9):5629-35.

78. Yildiz E, Bardak H, Gunay M, Bardak Y, Imamoglu S, Ozbas H, et al. Novel zinc finger protein gene 469 (ZNF469) variants in advanced keratoconus. Curr Eye Res. 2017;42(10):1396-400

79. Yu X, Chen B, Zhang X, Shentu X. Identification of seven novel ZNF469 mutations in keratoconus patients in a Han Chinese population. Mol Vis. 2017;23:296-305.

80. Arbab M, Tahir S, Niazi MK, Ishaq M, Hussain A, Siddique PM, et al. TNF-a genetic predisposition and higher expression of inflammatory pathway components in keratoconus. Invest Ophthalmol Vis Sci. 2017;58(9):3481-7.

81. Guan T, Ma ZW, Ding SP. Analyses of coding sequence point mutation and polymorphism of TGFBI gene in Chinese patients with keratoconus. Zhonghua Yi Xue Yi Chuan Xue Za Zhi. 2011;28(2):152-5.

82. Lechner J, Bae HA, Guduric-Fuchs J, Rice A, Govindarajan G, Siddiqui S, et al. Mutational analysis of MIR184 in sporadic keratoconus and myopia. Invest Ophthalmol Vis Sci. 2013;54(8):5266-72.

83. Pathak D, Nayak B, Singh M, Sharma N, Tandon R, Sinha R, et al. Mitochondrial complex 1 gene analysis in keratoconus. Mol Vis. 2011;17: 1514-25.

84. Saravani R, Hasanian-Langroudi F, Validad MH, Yari D, Bahari G, Faramarzi M et al. Evaluation of possible relationship between COL4A4 gene polymorphisms and risk of keratoconus. Cornea. 2015;34(3):318-22.

85. Udar N, Atilano SR, Brown DJ, Holguin B, Small K, Nesburn AB, et al. SOD1: a candidate gene for keratoconus. Invest Ophthalmol Vis Sci. 2006:47(8):3345-51.

86. Vincent AL, Jordan C, Sheck L, Niederer R, Patel DV, McGhee CN. Screening the visual system homeobox 1 gene in keratoconus and posterior polymorphous dystrophy cohorts identifies a novel variant. Mol Vis. 2013;19: 852-60.

Ready to submit your research? Choose BMC and benefit from:

- fast, convenient online submission

- thorough peer review by experienced researchers in your field

- rapid publication on acceptance

- support for research data, including large and complex data types

- gold Open Access which fosters wider collaboration and increased citations

- maximum visibility for your research: over $100 \mathrm{M}$ website views per year

At $\mathrm{BMC}$, research is always in progress.

Learn more biomedcentral.com/submissions 